\title{
Rural Victorian service provider responses to the National Disability Insurance Scheme
}

Claire Quilliam* (Orcid no 0000-0002-7344-0133) and Lisa Bourke ${ }^{\text {a }}$ (Orcid no 0000-0003-0411-6193)

${ }^{a}$ University Department of Rural Health, University of Melbourne, Shepparton, Australia

*Address for correspondence: Dr Claire Quilliam, University Department of Rural Health, University of Melbourne, 49 Graham Street, Shepparton, Victoria, Australia 3630. Email: Claire.quilliam@unimelb.edu.au

\section{Biographies}

Claire Quilliam is a social researcher at the University Department of Rural Health, The University of Melbourne. Her research interests focus on disability service provision, frontline staff, and the rural health workforce.

Lisa Bourke is Director of the University Department of Rural Health at The University of Melbourne. Trained as a rural sociologist, she has experience in social research in rural communities across Australia and the U.S. Her research interests focus on social inclusion, the development of rural health as a discipline and power relations in rural communities.

\section{Acknowledgements}

The authors would like to thank all participants for their insightful contributions. We also acknowledge the Australian Government Department of Health for funding through the Rural Health Multidisciplinary Training programme.

This is the author manuscript accepted for publication and has undergone full peer review but has not been through the copyediting, typesetting, pagination and proofreading process, which may lead to differences between this version and the Version of Record. Please cite this article as doi: $\underline{10.1002 / A J S 4.107}$

This article is protected by copyright. All rights reserved 
DR. CLAIRE QUILLIAM (Orcid ID : 0000-0002-7344-0133)

Article type : Original Article

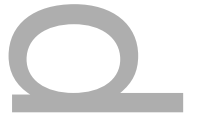

Rural Victorian service provider responses to the National Disability Insurance Scheme

\begin{abstract}
The National Disability Insurance Scheme (NDIS) has transformed the nature of funding available to health and human service organisations to provide services to people with disability in Australia. However, there is relatively scant literature on the rural implementation of the NDIS, particularly how rural NDIS service providers are affected by the NDIS. Researchers conducted semi-structured interviews with 20 health professionals employed by rural providers, and analysed data using rural and remote health and organisational change frameworks to understand how rural providers were impacted by and responded to the NDIS. The findings suggest rural providers were impacted to differing extents and responded to the NDIS in different ways. Participants reported that disability and community health services were affected more than hospitals and private allied health practices. Impacted rural providers responded by changing the nature and types of services, service processes, their workforce, and redefining organisational characteristics. Impacted rural providers may require additional support to continue providing services, and those less impacted may require other incentives to better engage with the NDIS. Rural proofing of NDIS policy could reveal suitable supports and incentives to ensure rural people with disability can access required services.
\end{abstract}




\section{Keywords}

Access; National Disability Insurance Scheme; rural proofing; rural NDIS service providers; rural people with disability.

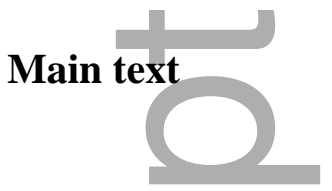

\section{Introduction}

The National Disability Insurance Scheme (NDIS) was developed to transform the Australian disability services landscape (Australian Government Productivity Commission [AGPC] 2017). By 2023, the NDIS is expected to provide individualised funding for services to 500,000 people with disability who qualify as an NDIS "participant", and other supports to people with disability outside of the scheme (National Disability Insurance Agency [NDIA] 2019a, p. iii). Along with approximately one-third of Australians, some NDIS participants live in non-metropolitan locations of Australia (Australian Bureau of Statistics 2017). However, the implementation of the NDIS in rural contexts may face a number of challenges because it requires the development of NDIS service markets in areas where service demand and availability may be low (Carey et al. 2017). The generalist approach often seen in rural service delivery (see Mitchell, et al. 2018) suggests the work to develop rural NDIS markets may need to involve both human and health service organisations in these areas. Understanding the complex processes that impact implementation of the NDIS in rural areas is important to ensure rural people with disability realise their right to access services to participate in their community. This is consistent with Article 19 of the Convention on the Rights of Persons with Disabilities ([CRPD], United Nations 2007). This paper seeks to contribute to understanding the NDIS in rural areas through the perspectives of NDIS service providers in non-metropolitan Victoria. Bourke et al.'s (2012) rural and remote health framework is used to examine the contextual processes relevant to rural settings, including the impact of and response to change stemming from the new national disability policy. This framework (Bourke et al. 2012) connects broader social and economic policies with rural community actions and is applicable to interrogate the impacts of the NDIS policies in rural locations. 


\section{Framework of rural and remote health}

Bourke et al.'s (2012) framework identifies six concepts that interact in the practice of rural health: i) geographic isolation (the geographical context), ii) the rural locale (local people and community), iii) local health responses (local health services and actions), iv) broader health systems (regional, state and national health strategies, organisations and initiatives), v) broader social structures (social norms, resources and relations that influence social processes, organisation and behaviours), and vi) power (present in all actions that enables and constrains action and change). The framework draws on Giddens' (1986) theory of structuration to connect individual actions with broader structures and provide a perspective of power that is simultaneously enabling and constraining. The interaction of these concepts provides a comprehensive perspective of rural health and identifies how change in one area influences change in others.

This study focuses on the impact of change in the broader health system (the NDIS) on local health responses (rural NDIS disability service providers) in nonmetropolitan Victoria, within Bourke et al.'s (2012) rural and remote health framework. The NDIS has changed the nature of funding that is available to health and human service organisations to provide services to people with disability (Mavromaras et al. 2018), from mostly block funding and some individualised funding (Fisher et al. 2010) to predominantly individualised funding delivered through a fee-for-service, marketbased model (AGPC 2017). It is argued that the funding made available through the NDIS will increase service demand, foster competition between service providers, drive market development, and result in people with disability having choice and control over the services they use (Department of Social Services 2019). However, questions have been raised about the extent to which the NDIS principles of choice and control (NDIS Act 2013) will guide implementation in rural and remote areas of Australia, where choice, access, and availability of specialised services is more limited (Bourke et al. 2012, National Rural Health Alliance 2013, Wakerman et al. 2008).

Changes in the broader health system introduced by the NDIS are consistent with the personalisation agenda (David and West 2017) within the broader social structures in Australia, and internationally. Broader social structures comprise macro level social beliefs, ideas, systems and processes that contribute to policy development — in this case — individualised, fee-for-service disability policy. The personalisation agenda is underpinned by two ideas: 1) social justice, often with a focus 
on human rights, individualisation and citizen autonomy through increased choice and control over services, and 2) marketisation, with a focus on efficiency though reduced government involvement, privatisation, and user pays systems (Mladenov et al. 2015). Needham and Dickinson (2018) suggested personalisation sub-narratives in Australian disability policy have focused on minimising the financial risks of disability and 'risk pooling' through insurance mechanisms, rather than providing choice and control over services for people with disability, as illustrated in English policy narratives. This combined with Mladenov et al.'s (2015) point that historically, marketisation has overridden social justice in policy underpinned with personalisation, suggests there is a need to closely observe the implementation of the NDIS in different Australian contexts to ensure all people with disability benefit from the NDIS.

Changes in the broader health system impact the ways in which organisations in rural areas react or reproduce healthcare, described here paper as local health responses (Bourke et al. 2012). Rural health and human service organisations in the NDIS market are local services responding to the change in policy. Referred to in this paper as rural NDIS service providers or rural providers, they are a collection of diverse NDIS policy actors with their own forms of knowledge on the implementation process. Rural providers range in size, structure, focus, geographical contexts, employ rural professionals from differing disciplines, and include for example, disability service organisations, community health organisations, private allied health practices and hospitals (NDIA 2019c). Rural providers, like human service organisations more generally, may respond to changes in the surrounding environment to remain relevant and meet service user needs (Hasenfeld 2010). Responses may range in scale from fine tuning organisational processes, to more incremental adjustments in response to the changing environment, and to complex changes including transformation to one part or revolutionary changes throughout a whole organisation (Dunphy and Stace 1993, pp. 13-14). Given the voluntary nature of participation in market economies (Brunsson 2009), both rural and metropolitan-based providers may expand or narrow service provision, or exit the market entirely. However, the latter response by rural providers could have pronounced consequences for rural people with disability who may be unable to access timely services, considering rural markets may already be "thin" (Carey et al. 2017, p. 198), and state government funded services may be unavailable (Mavromaras et al. 2018). Rural providers can determine the extent of their NDIS participation, although they may also shoulder some responsibility to ensure services 
are available for rural people with disability (e.g., Dew et al. 2016, Dew et al. 2014, Gallego et al. 2015).

Changes in the broader health system work differently in diverse geographical contexts that are shaped by the local environment, population size and distribution, distance to larger centres and services, and transport complexities (Bourke et al. 2012). Similarly, changes in the broader health system impact the rural locale through the beliefs, actions, reactions and interactions of local people with disability, their family members and other local residents - be it acceptance, resistance, apathy or a mixture of actions. Rural people with disability have experienced reduced choice and control over NDIS services, particularly Aboriginal and Torres Strait Islander people with disability (e.g., Gordon et al. 2019, Townsend et al. 2018, Warr et al. 2017). Family members of people with disability have highlighted poor access to services in rural areas (e.g., Gallego et al. 2017, Warr et al. 2017).

Finally, power is the ability to act, resist or promote change at all levels (Bourke et al. 2012). While not visible or static, power is negotiated daily to reproduce and/or rupture health behaviours, health care, health policy and health narratives. Of particular interest are the actions, resistance, changes and adaptations of rural providers to the NDIS implementation. A study by Dintino et al. (2019) found rural health professionals employed by rural NDIS service providers felt powerless because they struggled to meet service demand in their community, and were limited in capacity to ensure individual people with disability received adequate service funding. Power (and powerlessness) is embedded in the other concepts and emerges through actions to change, resist and negotiate at each level.

The six concepts within Bourke's rural and remote health framework clearly contribute to implementation of the NDIS in non-metropolitan Victoria. However, the focus here is on the impact of the NDIS policy (broader health systems) on rural providers, and their response to this impact (local health responses), alongside the geographical context, rural locale and broader social structures and embedded with processes of power. Thus, this study analysed the perspectives of those working in rural NDIS service provision in non-metropolitan Victoria to address the research question: how have rural NDIS service providers been impacted by, and responded to, the implementation of the NDIS? 


\section{Methods}

The study was part of a broader project that also explored changes to rural nursing and allied health student placements in rural Victorian NDIS service providers under the NDIS (Quilliam and Bourke 2019). The [University name withheld for review process] Human Ethics Advisory Group provided approval to conduct the study in 2017 (ID: $1750733.1,1750733.2)$.

\section{Study design}

We adopted a qualitative, exploratory research approach, including semi-structured interviews with a range of managers, educators and clinicians employed by rural providers to understand their perceptions on the impact of the NDIS on rural providers, and their response to it. Data were analysed via several analysis techniques and conceptual frameworks, including Hsieh and Shannon's (2005) directed content analysis techniques, Bourke et al.'s (2012) rural and remote health framework, Grbich's (2013) enumerative content analysis techniques, and Dunphy and Stace's (1993) organisational change model.

\section{Participant recruitment}

We drew on local knowledge and publicly available data on the internet to identify rural Victorian NDIS service providers. The term 'rural' is used to refer to nonmetropolitan areas of Victoria. withheld] telephoned 45 rural providers and asked to speak with potential participants involved with managing the NDIS service transition, employee professional development or facilitation of student placements. Fifteen rural providers did not respond to the author's telephone call and representatives from another 14 rural providers declined participation for a variety of reasons, including a lack of capacity due to the NDIS transition and potential participants feeling unsure of their capacity to offer meaningful insight on the research topic. The participant sample was drawn from 16 organisations, including six community health services, four hospitals, three disability services, and three private allied health practices. At the time of data collection (February to June 2018), the NDIS was approximately six-months from roll out in one rural region included in the study, and had been rolled out for sixnine months in other regions. Rural providers involved in the study had recently transitioned or were in the process of transitioning to the NDIS. withheld] verbally 
explained the study to potential participants within these organisations and invited them to meet face-to-face at a suitable time and place talk further about the study. The sample consisted of 20 health professionals employed by rural Victorian service providers funded at least partly by the NDIS. Nine participants held program management or director roles, seven held student, volunteer, or staff professional development coordination roles, two held roles predominately focused on allied health service provision, and two held practice management roles. Eleven participants had clinical backgrounds in either nursing or allied health including speech pathology, occupational therapy, physiotherapy, exercise physiotherapy, and social work.

\section{Data collection}

Face-to-face, semi-structured interviews were conducted with 20 health professionals. Interviews ranged between 25 and 90 minutes in length. withheld] asked participants seven main questions regarding the impact of the NDIS on their employing organisation, and organisational responses including changes to service provision and non-direct service activities. Prompting questions were asked to seek clarification on key terms used or expand on points raised by participants (Seidman 2013). With participant permission, initials withheld] audio-recorded and took hand-written notes during interviews. Professional services were employed to transcribe the audio recordings verbatim. withheld] removed identifying data, such as participant names, service names and locations, from transcriptions.

\section{Data analysis}

initials withheld] analysed interview data in line with directed content analysis techniques described by Hsieh and Shannon (2005), and using Bourke et al.'s (2012) remote and rural health framework concepts of geographic context, the rural locale, broader social structures, the impact of the broader health systems (NDIS) on rural providers, and local health (and human service) responses to the NDIS as predetermined conceptual categories. As demonstrated by Bourke et al. (2012), we used the framework concept of power as a connecting concept and identified power relations within the other categories. withheld] used enumerative content analysis techniques (Grbich 2013) to further analyse data within the broader health systems category to identify the number of participants that felt the NDIS had barely or not impacted their organisation, that were unsure whether the NDIS had impacted, and the number that felt 
the NDIS had significantly impacted their organisation. Dunphy and Stace's (1993) organisational change model was selected to illuminate nuances within local health responses based on four scales of organisational change: i) ongoing process of fine tuning to maintain consistency between strategy and processes, ii) incremental adjustments that modify strategies, structures and management processes, iii) modular transformations leading to major realignment of one or more departments, iv) corporate transformations that radically shift strategies and processes throughout a whole organisation (pp. 913-14). Like the Bourke et al. (2012) framework, Dunphy and Stace's (1993) model examines macro and micro level changes in an organisation and views these changes as interrelated. Both authors reviewed the relevance of the findings to the research questions and agreed they offered insight into rural health professional experiences of the impact of the NDIS on rural Victorian NDIS service providers and their responses

\section{Results}

In this section, we illustrate how the NDIS interacts with the geographical context, rural locale and broader social structures to shape service provision in rural Victoria. We then explore the impact of the NDIS on rural providers as a component of broader health systems, and rural service provider responses to the NDIS as local health responses.

\section{Geographical context}

Thirteen rural providers provided services in regional centres, of which many also provided services in towns surrounding these centres. Three rural providers provided services in towns located $50 \mathrm{kms}$ on average from a regional centre. The size of the town was relevant to the impact that the NDIS had on rural providers, and how their organisation responded to it. Participants working in smaller towns felt existing health and human services in their town were relatively powerless to meet local NDIS service demand. Geographically isolated towns described by participants generally comprised one health focused service provider that was unprepared to rapidly expand disability service provision to support NDIS participants, due to inadequate infrastructure, including a lack of physical space and equipment. These towns also generally comprised one or a few small private allied health service providers with little capacity to provide a range of NDIS services, often due to a shortfall in qualified health 
professionals. This meant NDIS participants needed to travel frequently-either 20 minutes to the next town, or up to a few hours to a regional centre to access services. Many participants were concerned about the impact of constant travel on rural families, and noted that travel was not possible for many rural people with disability:

We don't have a lot of private providers in [town] and I know the private providers in [another town] and [another town] are getting quite full. ...They're [families are] then having to travel and go elsewhere, so that [service] access is impacted for them. (Hospital employee)

The NDIS is sort of predicated on the fact that empowering clients will mean they will go and find their services, but typically, our clients aren't able to do that. That's why they need physiotherapy or occupational therapy-it's because they can't travel out of their home or out of their town. (Community health service employee)

\section{The rural locale}

Health professionals observed the implementation of the NDIS alongside rural people with disability and their families in the communities that their organisation served. Many participants acknowledged that the NDIS provided funding for services to rural people who had not previously accessed services. However, some also noted NDIS participants requiring similar services sometimes received different funding amounts, and others experienced unexplained funding cuts. These participants suggested that funding inequity and changes jeopardised service access for rural people with disability in their rural communities, particularly for those without family to support navigation of the NDIS, and families with multiple NDIS participants. One participant noted how some families who received inadequate service were made to feel so powerless that they felt they were no longer able to provide care for their family member:

If we can't put in those supports when needed for carers ... there could be a higher risk of relinquishment ... We've already had a couple of families threaten [to do] that because it is difficult ... They're not getting the same services that they had. (Community health service employee)

\section{Broader social structures}

Some participants critically reflected on key ideas underpinning the NDIS. In particular, 
they noted the shift to individualised service provision, including an increased focus on the rights of NDIS participants to choose services, and the adoption of a privatised service provision model, including a user-pays system. A few participants noted that these ideas were often in tension, and limited the capacity of rural providers to support NDIS participants flexibly in day-to-day practice:

One of the other really important things about the NDIS was it had to be delivered as a business model. You had to deliver units [of service], and only those units. A person [employee] couldn't stay 20-minutes longer because somebody was distressed, or they wanted to have an extra-long walk.... It had to be confined to a cost-effective model. (Community health service employee)

\section{Broader health systems (NDIS impact on rural providers)}

The NDIS had impacted rural providers to varying extents. Ten participants-four hospital employees, three private allied health practice employees, two community health service employees, and one disability service employee - felt the NDIS had barely or not impacted their organisation, or were unsure whether the NDIS had impacted their organisation due to the NDIS transition requiring little effort. These participants were generally employed by organisations familiar with the fee-for-service funding model or larger organisations, and noted how impacts were cushioned by existing funding processes and diversity of funding streams:

NDIS is basically what I classify as a third-party organisation that pay for other people's accounts. ... The majority of people on the NDIS with us have been clients of ours through a different third party. ... Instead of sending it to [one party], you're sending it to [another party]. (Private practice employee)

The other 10 participants — seven community health service employees and three disability service employees - felt the NDIS had significantly impacted their organisation, largely because it required a transition to a new funding model. These participants were generally employed by organisations with an increasing reliance on NDIS funding, or those unfamiliar with the fee-for-service funding model:

Agencies like us are not set up to be invoicing individual clients. We've never done it. (Community health service employee) 
These participants described how their organisations were relatively powerless to address concerns with the NDIS funding model. They explained that the funding lacked 'flexibility' to support service users in a responsive manner, and 'fat' to carry out nondirect service activities or properly cover staffing costs as the previous funding model offered:

There was a little bit more flexibility [with previous funding]. You might [have] been able to use someone's ISP or something to fund [other services], if a family had financial issues. Now, the NDIS will fund, basically, to get to the activity [done, pay] the workers. (Community health service employee)

[The new funding] was barely enough to pay a person [employee] for their exact time. It didn't cover their transport, ... supervision [or] training... We also couldn't monitor them. (Community health service employee)

\section{Local health and human service responses to the NDIS}

Health professionals' perceptions revealed that rural provider responses to the NDIS varied. Those who felt the NDIS had barely or not impacted their organisation generally explained their organisation responded by undergoing minor changes. Others described how their organisation responded by making significant changes. These changes will now be illustrated within the four scale types of Dunphy and Stace's (1993) organisational change model: fine tuning, incremental adjustment, modular transformation, and corporate transformation.

Fine tuning

Some participants explained that their organisation experienced no changes to organisational mission, structure, or services provision in response to the NDIS, other than minor changes to the processes of receiving funding. A few highlighted how their organisation fined-tuned service processes through existing employee dialogue mechanisms, such as team meetings, to prepare for the NDIS implementation. One participant described how their organisation clarified their mission to meet the needs of rural locale more broadly_including people that were not NDIS participants, and decided to only offer one NDIS service to remain focused on this mission. A few others explained how their organisation considered but decided against developing services in 
smaller towns due to the logistical effort required to orchestrate individualised service provision:

No, I don't believe our services have changed. I think we're still offering the same services that we've always offered. Now it's just comes in under the NDIS. (Community health service employee)

To be brutally honest, we only offer one NDIS service... We chose not to offer [ [the others]. (Private practice employee)

If there's a demand in [that town], maybe you could set up an office [there], ... see five people on the same day in [the town]. Well, that all works well in theory, but it doesn't work in reality. There aren't five people available on a Wednesday.... You might want to go and visit that child at kinder, but they're not at kinder on a Wednesday. Mum and Dad might both work on a Wednesday and are not available for you to come. ...It's not as simple as just saying, 'We'll see all the people on the same day, or set up an office in [the town]'....It's those kinds of [people in] out-lying towns to regional areas, that are disadvantaged. (Disability service employee)

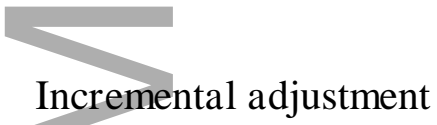

Some participants described how their organisation made incremental adjustments to remain relevant and financially viable in the new policy environment. These adjustments included merging teams to reflect new service delivery practices, and undertaking processes involved in registering or not registering as an NDIS service provider. Participants described how these adjustments occurred within a specified period of time and involved significant organisational learning:

Our service has changed. We've had a service [re]structure so now, for us, we have aged, and disability blended more together. (Community health service employee)

That three months of starting user names and adding [the practice] and getting it out there to NDIS clients that we were actually NDIS providers; by far, was the hardest thing. Now, in five minutes, I can get online, get a service request done and get money into my account. (Private practice employee) 
We made a decision not to be an NDIS provider ... our organisation deemed that it wasn't financially strong enough for us to do that. (Community health service employee)

\section{Modular transformation}

Participants, particularly from community health and disability service organisations, explained how parts of their organisation underwent transformative changes. These changes included transitioning to the fee-for-service funding model, managing funding uncertainty, increasing the amount of service provision, and offering new services to meet service demand in departments traditionally offering disability services. However, some participants described a sense of powerlessness when they explained that staffing shortages and limited funding had restricted their organisation from increasing and developing new services. Others explained how their organisation had narrowed the provision of services to fit within the funding arrangements, for example, to NDIS participants self-managing funding, or to allied health services requiring less preparation time. A few participants described how their department had closed services and stopped providing financially unsustainable in-kind services:

Some group programs we no longer run because the amount of money the NDIS will pay for that [service] doesn't cover the cost of delivering it. (Disability service employee)

We are accessing disability funding through the NDIS, but only for individuals who are self-managed or are plan managed. (Community health service employee)

We used to carry individuals. If they couldn't pay... we'd write off debts. We can't write off debts now. So, if they're not paying their bills, then we can't continue to service them. (Community health service employee)

Many participants explained how their departments transformed existing service processes by adopting new information technology systems, increasing billable hours, and reducing non-direct activities such as paperwork, service preparation tasks, and supervision of students on placement. Other adaptions included reductions to service footprint and travel time: 
We are working with staff to actually build it [billable hours] up... Other people have set it at 80 [per cent]. (Disability service employee)

If you happen to live a bit further away, then we are limited in the amount of service that we can provide in that model because of the cap on travel.

(Disability service employee)

Some rural providers adopted targeted promotional strategies. For example, one participant described how health professionals prompted NDIS participants to request the inclusion of particular services in their plans:

The allied health manager has had to spend a lot of time talking to her clinicians about making sure that clients have got their podiatry [service requirements] included in their plan. (Community health service employee)

Many rural providers adapted their workforce and employee recruitment processes. Some offered redundancy packages to existing employees - a process that had an emotional toll on remaining employees. Others recruited new employees according to demand, which typically meant recruiting fewer managers, administrators, and social workers, and more speech pathologists and occupational therapists - although some participants found it difficult to recruit allied health professionals:

We made seven people redundant. It was a really significant, awful time for us as an organisation. (Community health service employee)

We are recruiting to the waiting lists now.... Our longest wait list at the moment is in children's services for speech therapy. (Disability service employee)

Corporate transformation

A few participants from community health and disability service organisations described how their whole organisation had radically transformed in response to the NDIS. Organisations had adopted market-based identities and differentiated themselves from others to reflect the competitive service environment introduced by the NDIS and to attract NDIS participants. They explained how this transformation altered their organisation's defining feature - their not-for-profit service model: 
We're no different moving forward to any other private provider. We're in the same market, after the same dollars as everybody else... The NDIS has seen the end to that [model of care]. (Community health service employee)

Now it's about promoting that [service] and making people choose [the organisation]. (Community health service employee)

One participant illustrated the power available to established rural providers when they described how the competitive NDIS service environment exacerbated existing issues and led to the decision not to collaborate with new rural providers:

Staff in the past have relied on their knowledge that they've built up over time to know where other providers are in the community for certain services that people might need that perhaps we couldn't help them with. But what's happened with the NDIS is there might have been a really great [local] service provider but they've chosen not to be NDIS registered, so sometimes there have been brand new organisations that have sprung up in the area, because they're [an] NDIS provider and it's an opportunity for them to expand. ...It's probably a little bit indicative of rural mentality that people don't trust newcomers...

Particularly if they [the new NDIS service provider] look like they've only sprung up because there's a business opportunity created by the NDIS - they're even more hesitant to recommend them. That's a very rural thing. (Community health service employee)

\section{Discussion}

This paper used Bourke et al.'s (2012) rural and remote health framework to explore the impacts of change introduced by the NDIS on rural Victorian NDIS service providers, and their responses to this change, alongside other interacting concepts from the framework including geographical context, the rural locale, broader social structures, and power. The findings demonstrated how geographical isolation manifested in size of the community, availability of local services and accessibility of services in larger centres. The rural locale identified the importance of consumer responses to the NDIS and health professionals' perspectives of consumers' ability to navigate the NDIS in the implementation period. Health professionals' perceptions highlighted an awareness of the broader social structure ideas underpinning the NDIS, including individualised 
service provision and privatisation, and the tensions between these and with existing practices. The broader health systems were found to influence the level of service funding and to have a varied impact on rural providers, with health professionals' perceptions suggesting disability service and community health services were impacted more so than hospitals and private allied health practices. Local health responses varied, with some rural providers experiencing little change, others transforming their services, departmental and organisational processes, and some deciding not to register as an NDIS service provider.

Underpinning these responses, changes and reproduction of services was power-the capacity of people with disability, rural providers and others to shape, seek out, adapt or discontinue services. The diversity of responses of rural providers to the NDIS highlighted the diverse power relations at play. On the one hand, reflecting findings by Dintino et al. (2019), participants described a sense of powerlessness to meet increased demand for boutique services or those requiring significant travel, timeconsuming preparation, and non-direct service activities. This suggests broader health systems and geographical contexts influence rural providers' adaptability to change, and possibly steer them toward a generalist care model to meet the needs of rural people with disability that are easily met but not those outside of these parameters, as seen in rural health care more generally (e.g., Mitchell et al. 2018).

On the other hand, participants demonstrated their organisations' power to make decisions about the nature of their engagement with the NDIS, including relationships with other rural providers and participation in NDIS markets; a process that was traumatic for some rural providers. While having freedom to enter and exit markets like the NDIS is important (Gash et al., as cited in Carey et al. 2018), this finding supports suggestions by Carey et al. (2018) that a market-based approach may not benefit rural people because rural communities may not see the same kind of market growth as metropolitan centres. However, these responses occurred during a time of significant change for many rural providers and may not offer any indication of the state of rural NDIS markets in the future. Recent increases in NDIS support cost prices and rule changes that allow service providers to charge for some non-direct service activities (NDIA, 2019b) may partially relieve the issues described by participants. However, these changes may come too late for rural providers that have decided not to register as an NDIS service provider or to participate in a limited way, and for those that have deregistered, closed services and undergone significant workforce changes. Conservative 
funding and strict rules during the implementation period could have a long-term impact on the capacity of rural providers to deliver NDIS services, because it may take significant time to rebuild a rural workforce capable of providing quality services to rural people with disability (Cosgrave et al. 2018, Lincoln et al. 2014).

A particularly interesting finding relating to local health responses was the hesitancy of established rural providers to recommend services by new rural providers. This could be viewed as a gatekeeping exercise working against service access for rural people (Vecchio 2013), or if viewed through an ethics of care lens (Tronto 2010), as rural providers drawing on particularised knowledge and actively shaping local service development to meet support requirements of rural community members with disability (Ife 2009). Through the latter view, these activities could be considered as a potentially helpful place-based means of guiding the development of contextually-appropriate NDIS services. However, for this to occur, rural providers must remain aware of existing power-relationships, remain open to new ways of service provision and focused on the end purpose of service provision (Tronto 2010), which is to ensure rural people with disability have the support they require to lead meaningful lives. This finding suggests there may be varied responses to changes in national disability policy, and points to the need for more flexible policy to support this work (National Rural Health Alliance 2013).

Overall, the findings of this study suggest issues of access to services for rural Victorian people with disability may, in some ways, have been made more complex by the NDIS, and exacerbated by local service responses. Rural people who self-manage NDIS funding may experience more choice over services because they can purchase services from non-registered providers, as pointed out by David and West (2017). However, those with funds managed by the NDIA may not have the same opportunity to access services within a reasonable geographical distance from their own community, or in a timely manner, and this may result in reduced choice and control over services, as noted by Warr et al. (2017). Further, the finding that in-kind services may be reduced for rural people who are ineligible for NDIS funded supports, suggests the development of further layers of service inequity, as Carey et al. (2017) discussed. These findings suggest the Australian Government may find difficulty meeting the obligation under Article 19 of the CRPD (United Nations 2007) to ensure all Australians with disability have access to services to participate in their communities. 
The NDIA and other government bodies have implemented a range of strategies to address rural NDIS service market failure described by some participants in this study. The NDIA has committed to increasing funding flexibility to cover travel costs (Ministers for the Department of Social Services 2020), although how this will impact rural service provision remains unclear. The NDIA (2018) has considered directly commissioning service providers where necessary, although this study suggests they may struggle to find willing rural providers for this work, given the logistical barriers with travelling long distances to provide individualised services. Participants rarely spoke of using federal and state government grants or other supports during their transition to the NDIS. This could potentially reflect the relative lack of grants available at the time of date collection compared to recent times (see Boosting the Local Care Workforce Program 2019, Victorian Government 2019), or a lack of capacity within rural providers to apply for grants under the NDIS funding model. Taken together, the complex issues raised in this study suggest current government policy aimed at developing the NDIS service markets in rural areas of Australia may warrant further attention.

Rural providers significantly impacted by the NDIS, including disability services and community health service organisations, may require immediate support to rebuild the workforce, develop new or simply continue to provide services. Policymakers could consider offering impacted rural providers additional transition funding and, as suggested by Carey et al. (2019), discretionary power to use funding flexibly to overcome rural NDIS implementations issues. Other options include offering block funding in rural areas experiencing market failure, and encouraging impacted rural providers to lead service development, as suggested by the AGPC (2017), and Carey and Malbon (2018). Block funding used within place-based approaches described by Greenwood and Levin (2007) could foster collaboration between stakeholders in the rural locale and harness local knowledge in service development work. Rural providers negligibly impacted, such as hospitals and particularly allied health professionals working within private allied health practices, as noted by Dew et al.'s (2016), could have further capacity to provide NDIS services in rural areas. These providers could be supported to engage with the NDIS, to respond to rural service demand and expand their service range, perhaps through the provision of business supports and information on service price increases and rule changes that allow billing for some non-direct activities, such as case notes (NDIA 2019b). These strategies, although somewhat reactive in 
nature, may support a broader range of rural providers to provide services to rural NDIS participants. However, a rural proofing approach to policy development, drawing on Dew et al.’s (2016) framework for developing rural NDIS services provided by therapists, may support policymakers to engage rural stakeholders to explore areas of need and develop NDIS policy to equitably benefit rural people with disability alongside their metropolitan counterparts.

\section{Strengths and limitations}

Applying Bourke et al.'s (2012) rural and remote health framework in this study has helped to unpack some of the complexities involved with implementing the NDIS in a rural area. The framework illustrates that change in one concept such as broader health systems influences change in others such as local health responses, and alongside other concepts, including the geographical context, rural locale, broader social structures and power. It highlights how the NDIS has impacted, in diverse ways, on everyday lives of those involved in rural service provision, and also how further changes could enable rural providers to further develop NDIS services in rural areas. However, the study was small, and only comprised the perspectives of health professionals employed by rural disability services, community health services, hospitals and private allied health practices in one Australian state jurisdiction. The high number of rural providers that chose not to participate in the study may have impacted the findings in some way, although the sample provided sufficient data to offer exploratory insights into the ways that the NDIS has affected rural providers in Victoria. The study captured a snapshot of the impact of the NDIS in 2018, when the NDIS was at various stages of implementation in rural Victoria. Future studies could include the perspectives of health professionals in other jurisdictions, and those remotely-based, and of rural NDIS participants. Jointly exploring the perspectives of rural people with disability and providers could reveal important insight into the processes of co-developing sustainable rural NDIS services.

\section{Conclusion}

Rural Victorian health professional perspectives suggest rural NDIS service providers have been impacted by and responded to the NDIS to varying extents and in different ways. Additional incentives may encourage negligibly impacted rural providers to better 
engage with the NDIS. The provision of immediate resources may support impacted rural providers to continue to provide services, develop new services, and rebuild their workforce where necessary. The rural proofing of NDIS policy may go some way to ensure rural people with disability can access services to live meaningful lives.

\section{Declaration of Interest}

The authors declare no conflict of interest in this study.

\section{References}

Australian Bureau of Statistics (2017) Regional Population by Age and Sex, Australia, 2017. Cat. No. 3235.0.

Boosting the Local Care Workforce Program (2019) Sector transition and employer support (STES) initiative transition assistance funding: transition assistance funding (accessed 9 November 2019). Available from: https://www.communitygrants.gov.au/grants/boosting-local-care-workforceprogram-transition-assistanc

Bourke, L., Humphreys, J. S., Wakerman, J. and Taylor, J. (2012) 'Understanding rural and remote health: a framework for analysis in Australia', Health \& Place, 18(3), 496-503.

Brunsson, N. (2009) Reform as routine: organizational change and stability in the modern world, Oxford University Press. Available from: https://www.oxfordscholarship.com/view/10.1093/oso/9780198296706.001.000 1/oso-9780198296706.

Carey, G., Dickinson, H., Malbon, E. and Reeders, D. (2018) 'The vexed question of market stewardship in the public sector: examining equity and the social contract through the Australian National Disability Insurance Scheme', Social Policy \& Administration, 52(1), 387-407.

Carey, G. and Malbon, E. (2018) 'Strange magic: what can the emergence of 'magic concepts' tell us about policy implementation?' Policy Design and Practice, 1(3), 169-182.

Carey, G., Malbon, E., Reeders, D., Kavanagh, A. and Llewellyn, G. (2017) 'Redressing or entrenching social and health inequities through policy implementation? Examining personalised budgets through the Australian National Disability Insurance Scheme', International Journal for Equity in Health, 16(1), 192-204. 
Carey, G., Malbon, E. R., Weier, M., Dickinson, H. and Duff, G. (2019) 'Making markets work for disability services: the question of price setting', Health \& Social Care in the Community, 27(5), e716-e723.

Cosgrave, C., Maple, M. and Hussain, R. (2018) 'An explanation of turnover intention among early-career nursing and allied health professionals working in rural and remote Australia - findings from a grounded theory study,' Rural And Remote Health, 18, 4511-4528.

David, C. and West, R. (2017) 'NDIS self-management approaches: opportunities for choice and control or an Uber-style wild west?' Australian Journal of Social Issues, 52(4), 331-346.

Department of Social Services (2019) Growing the NDIS market and workforce: supporting the market to deliver innovative, people-centred services so that participants can achieve their goals (accessed 9 November 2019). Available from: https://www.dss.gov.au/disability-and-carers-programs-services-forpeople-with-disability-national-disability-insurance-scheme/growing-the-ndismarket-and-workforce-strategy.

Dew, A., Barton, R., Ragen, J., Bulkeley, K., Iljadica, A., Chedid, R. J., Brentnall, J., Bundy, A., Lincoln, M., Gallego, G. and Veitch, C. (2016) 'The development of a framework for high-quality, sustainable and accessible rural private therapy under the Australian National Disability Insurance Scheme', Disability \& Rehabilitation, 38(25), 2491-2503.

Dew, A., Bulkeley, K., Veitch, C., Bundy, A., Lincoln, M., Glenn, H., Gallego, G. and Brentnall, J. (2014) 'Local therapy facilitators working with children with developmental delay in rural and remote areas of western New South Wales, Australia: the 'Outback' service delivery model', Australian Journal of Social Issues, 49(3), 309-328.

Dintino, R., Wakely, L., Wolfgang, R., Wakely, K. M. and Little, A. (2019) 'Powerless facing the wave of change: the lived experience of providing services in rural areas under the National Disability Insurance Scheme', Rural \& Remote Health, 19(3), 5337-5347.

Dunphy, D. and Stace, D. (1993) 'The strategic management of corporate change', Human Relations, 46(8), 905-918.

Fisher, K. R., Gleeson, R., Edwards, R., Purcal, C., Sitek, T., Dinning, B., Laragy, C., D'aegher, L. and Thompson, D. (2010) Occasional Paper no. 29: effectiveness 
of individual funding approaches for disability support, Canberra, Australian Government Department of Families, Housing, Community Services, and Indigenous Affairs, Commonwealth of Australia.

Gallego, G., Dew, A., Lincoln, M., Bundy, A., Chedid, R. J., Bulkeley, K., Brentnall, J. and Veitch, C. (2015) 'Should I stay or should I go? Exploring the job preferences of allied health professionals working with people with disability in rural Australia', Human Resources for Health, 13(1), 53-66.

Gallego, G., Dew, A., Lincoln, M., Bundy, A., Chedid, R. J., Bulkeley, K., Brentnall, J. and Veitch, C. (2017) 'Access to therapy services for people with disability in rural Australia: a carers' perspective', Health \& Social Care in the Community, 25(3), 1000-1010.

Giddens, A. (1986) The constitution of society, Berkeley, University of California Press.

Gordon, T., Dew, A. and Dowse, L. (2019) 'Listen, learn, build, deliver? Aboriginal and Torres Strait Islander policy in the National Disability Insurance Scheme', Australian Journal of Social Issues, 54(3), 224-244.

Grbich, C. (2013) Qualitative data analysis: an introduction, 2nd ed., London, Sage. Greenwood, D. and Levin, M. (2007) Introduction to action research: social research for social change, 2nd ed., California, Sage.

Hasenfeld, Y.(2010) 'Organizational responses to social policy: the case of welfare reform', Administration in Social Work, 34(2), 148-167.

Hsieh, H. and Shannon, S. E. (2005) 'Three approaches to qualitative content analysis' Qualitative Health Research, 15(9), 1277-1288.

Ife, J. (2009) Human rights from below: achieving rights through community development, UK, Cambridge University Press.

Lincoln, M., Gallego, G., Dew, A., Bulkeley, K., Veitch, C., Bundy, A., Brentnall, J., Chedid, R. J. and Griffiths, S. (2014) 'Recruitment and retention of allied health professionals in the disability sector in rural and remote New South Wales, Australia', Journal of Intellectual \& Developmental Disability, 39(1), 86-97. Mavromaras, K., Moskos, M., Mahuteau, S., Isherwood, L., Goode, A., Walton, H., Smith, L., Wei, Z. and Flavel, J. (2018) Evaluation of the NDIS: final report, National Institute of Labour Studies, Flinders University (accessed 9 November 2019). Available from: https://www.dss.gov.au/sites/default/files/documents/04_2018/ndis_evaluation consolidated_report_april_2018.pdf. 
Ministers for the Department of Social Services (2020) Delivering the NDIS plan: flexibility in transport funding for NDIS participants (accessed 5 February 2020). Available from: https://ministers.dss.gov.au/media-releases/5471

Mitchell, O., Malatzky, C., Bourke, L. and Farmer, J. (2018) 'A modified Continuous Quality Improvement approach to improve culturally and socially inclusive care within rural health services', Australian Journal of Rural Health, 26(3), 206-210.

Mladenov, T., Owens, J. and Cribb, A. (2015) 'Personalisation in disability services and healthcare: a critical comparative analysis', Critical Social Policy, 35(3), 307326.

NDIA (National Disability Insurance Agency) (2018) National Disability Insurance Scheme market enablement framework (accessed 9 November 2019). Available from: https://www.ndis.gov.au/providers/market-information\#marketenablement-role-of-ndia-as-market-steward.

NDIA (National Disability Insurance Agency) (2019a) Annual report 2018-2019 (accessed 9 January 2020). Available from: https://www.ndis.gov.au/aboutus/publications/annual-report.

NDIA (National Disability Insurance Agency) (2019b) NDIS price guide 2019-20 (accessed 9 November 2019). Available from: https://www.ndis.gov.au/providers/price-guides-and-information\#ndis-priceguide-2019-20.

NDIA (National Disability Insurance Agency) (2019c) Provider lists (accessed 9 November 2019). Available from: https://www.ndis.gov.au/participants/working-providers/find-registeredprovider\#provider-lists.

National Disability Insurance Scheme Act 2013.

National Rural Health Alliance (2013) Delivering equitable services to people living with a disability in rural and remote areas: final project report (accessed 9 January 2020). Available from: http://ruralhealth.org.au/document/deliveringequitable-services-people-living-disability-rural-and-remote-areas-final-project. Needham, C. and Dickinson, H. (2018) 'Any one of us could be among that number': comparing the policy narratives for individualized disability funding in Australia and England', Social Policy \& Administration, 52(3), 731-749.

AGPC (Australian Government Productivity Commission) (2017) National Disability Insurance Scheme (NDIS) costs, Canberra, Commonwealth of Australia. 
Quilliam, C. and Bourke, L. (2019) The perspectives of National Disability Insurance Scheme service providers on student placements in rural Victoria. Shepparton, Department of Rural Health, University of Melbourne.

Seidman, I. (2013) Interviewing as qualitative research: a guide for researchers in education and the social sciences, New York, Teachers College Press.

Townsend, C., White, P., Cullen, J., Wright, C. J. and Zeeman, H. (2018) 'Making every Australian count: challenges for the National Disability Insurance Scheme (NDIS) and the equal inclusion of homeless Aboriginal and Torres Strait Islander Peoples with neurocognitive disability', Australian Health Review, 42(2), 227-229.

Tronto, J.(2010) 'Creating caring institutions: politics, plurality, and purpose', Ethics and Social Welfare, 4(2), 158-171.

United Nations (2007) Convention on the rights of persons with disabilities and optional protocol (accessed 9 November 2019). Available from: https://www.un.org/development/desa/disabilities/convention-on-the-rights-ofpersons-with-disabilities.html.

Vecchio, N. (2013) 'Gatekeepers to home and community care services: the link between client characteristics and source of referral', Australian Health Review, 37(3), 356-361.

Victorian Government (2019) Victorian regional readiness fund (accessed 9 November 2019). Available from: https://www.vic.gov.au/victorian-regional-readinessfund.

Wakerman, J., Humphreys, J. S., Wells, R., Kuipers, P., Entwistle, P. and Jones, J. (2008) 'Primary health care delivery models in rural and remote Australia-a systematic review', BMC Health Services Research, 8(1), 276-286.

Warr, D., Dickinson, H., Olney, S., Hargrave, J., Karanikolas, A., Kasidis, V., Katsikis, G., Ozge, J., Peters, D., Wheeler, J. and Wilcox, M. (2017) Choice, control and the NDIS (accessed 9 November 2019). Available from: https://socialequity.unimelb.edu.au/_data/assets/pdf_file/0008/2598497/Choice -Control-and-the-NDIS.pdf. 


\section{University Library}

\section{- M M N E R VA A gateway to Melbourne's research publications}

Minerva Access is the Institutional Repository of The University of Melbourne

Author/s:

Quilliam, C;Bourke, L

Title:

Rural Victorian service provider responses to the National Disability Insurance Scheme

Date:

2020-03-01

Citation:

Quilliam, C. \& Bourke, L. (2020). Rural Victorian service provider responses to the National Disability Insurance Scheme. AUSTRALIAN JOURNAL OF SOCIAL ISSUES, 55 (4), pp.439-455. https://doi.org/10.1002/ajs4.107.

Persistent Link:

http://hdl.handle.net/11343/276844 